\title{
NECESSIDADES DE INFORMAÇÃO E COMPETÊNCIA EM INFORMAÇÃOO DE PRODUTORES DE AVES INTEGRADOS DA AGROINDÚSTRIA SADIA S. A. DO OESTE DE SANTA CATARINA
}

\author{
NECESIDADES DE INFORMACIÓN Y \\ ALFABETIZACIÓN EN INFORMACIÓN DEL \\ PRODUCTORES DE AVES INTEGRADOS DE LA \\ AGROINDUSTRIA SADIA S. A. DEL OESTE DE \\ SANTA CATARINA, BRASIL
}

\begin{abstract}
Delsi Fries Davok - delsidavok@gmail.com Doutora em Engenharia de Produção pela Universidade Federal de Santa Catarina (UFSC). Professora da Universidade do Estado de Santa Catarina (UDESC).

Letícia Lazzari - letty.lazzari@gmail.com Bacharel em Biblioteconomia pela Universidade do Estado de Santa Catarina (UDESC). Bibliotecária do Instituto Federal de Santa Catarina (IFSC).
\end{abstract}

\footnotetext{
RESUMO

Introdução: Trata-se de um estudo de avaliação das necessidades de informação e a competência em informação de produtores de aves do sistema de integração da agroindústria Sadia S. A. do Oeste Catarinense.

Objetivo: Analisar as necessidades de informação e a competência em informação de produtores de aves do sistema de integração da agroindústria Sadia S.A. do Oeste Catarinense.

Metodologia: Estudo exploratório qualitativo, cujos instrumentos de coleta de dados utilizados foram a entrevista estruturada e um formulário para a caracterização dos sujeitos da amostra. Para a análise dos dados foi utilizada a técnica do Discurso do Sujeito Coletivo e um conjunto de indicadores para avaliação da competência em informação.

Resultados: Identificou-se que os avicultores têm necessidades de informação para a solução de problemas, para atualização e aperfeiçoamento do processo produtivo, e acerca dos objetivos futuros da empresa integradora. Quanto à competência em informação, constatou-se que os avicultores reconhecem
} 
parte das informações de que necessitam, porém, não o suficiente para o atendimento das suas necessidades.

Conclusões: Os avicultores, para serem competentes em informação, precisam desenvolver os seguintes aspectos: identificar uma variedade de tipos e formatos de fontes de informação potenciais, buscar informação utilizando uma variedade de métodos, refazer a estratégia de busca de informações quando necessário.

Palavras-chave: Agroindústrias - oeste catarinense. Sadia S. A. Avicultura. Competência em informação - avicultores. Necessidades de informação avicultores.

\section{INTRODUÇÃO}

Inicialmente caracterizada como um setor marginal, a avicultura firmou-se como uma das principais atividades econômicas do estado de Santa Catarina, definindo o Oeste Catarinense como a região centralizadora dessa produção.

Em consonância com o aumento de sua importância para o desenvolvimento estadual e sua participação na economia da Região Sul e do País, a avicultura se modificou e se desenvolveu, impactando em mudanças nesse setor produtivo. Essas transformações são oriundas também do desenvolvimento tecnológico e das exigências do sistema de mercado, principalmente, no que tange ao comércio exterior.

O produtor rural incorpora essas modernizações em sua propriedade por exigência da agroindústria, porém, muitas vezes alheio aos reais motivos dessa exigência, pois suas necessidades de informação nem sempre são supridas, criando-se assim uma lacuna no conhecimento desse indivíduo, impedindo-o de compreender a real importância das mudanças que estão ocorrendo na sua área de atuação e produção. Além da dificuldade na compreensão das mudanças que vêm ocorrendo nos sistemas produtivo e econômico, em decorrência da globalização dos mercados, a informação ou a falta desta, também pode interferir no desempenho do processo produtivo, sobretudo no desempenho das atividades cotidianas desses produtores. 
Entende-se, portanto, que o produtor rural necessita de informações a fim de atender e entender esses aspectos, pois, de posse de informações técnicas confiáveis, tem a possibilidade de: conhecer outras realidades e procedimentos capazes de agregar valor ao seu fazer diário; compreender as mudanças que ocorrem em sua área de atuação; acompanhar o desenvolvimento da avicultura; e satisfazer dúvidas, problemas e necessidades de informação identificadas no decorrer do desenvolvimento de suas tarefas.

No entanto, o acesso a informações para sanar lacunas no conhecimento requer do indivíduo o desenvolvimento de competências em informação para resolver situações problemas futuras.

Partindo dessa problemática e tendo em vista o valor que 0 acesso à informação pode agregar à produtividade e à qualidade de vida dos sujeitos, se apresenta as seguintes questões:

- Quais são as necessidades de informação dos produtores de aves, integrados da agroindústria Sadia S.A. do Oeste Catarinense para 0 desenvolvimento de suas atividades cotidianas?

- Qual é o perfil de competência em informação dos produtores de aves?

- Qual o perfil de competência em informação necessário para que os produtores de aves tenham acesso e possam fazer uso da informação oportuna e necessária?

Assim, a pesquisa que deu origem a este artigo objetivou analisar as necessidades de informação e a competência em informação da comunidade de produtores de aves do sistema de integração da agroindústria Sadia S.A. do Oeste Catarinense. 


\section{CONTEXTO DA PESQUISA}

Esta pesquisa se insere no contexto da região Oeste do estado de Santa Catarina, abordando, o sistema integrado de produção adotado pelas agroindústrias da Região, especificamente pela empresa Sadia S.A.

A história do Oeste Catarinense pode ser explicada com base no seu desenvolvimento econômico, ou nos quatro ciclos econômicos identificados na evolução histórica da região, como mostra a Figura 1.

Figura 1 - Linha do tempo dos ciclos econômicos do Oeste Catarinense

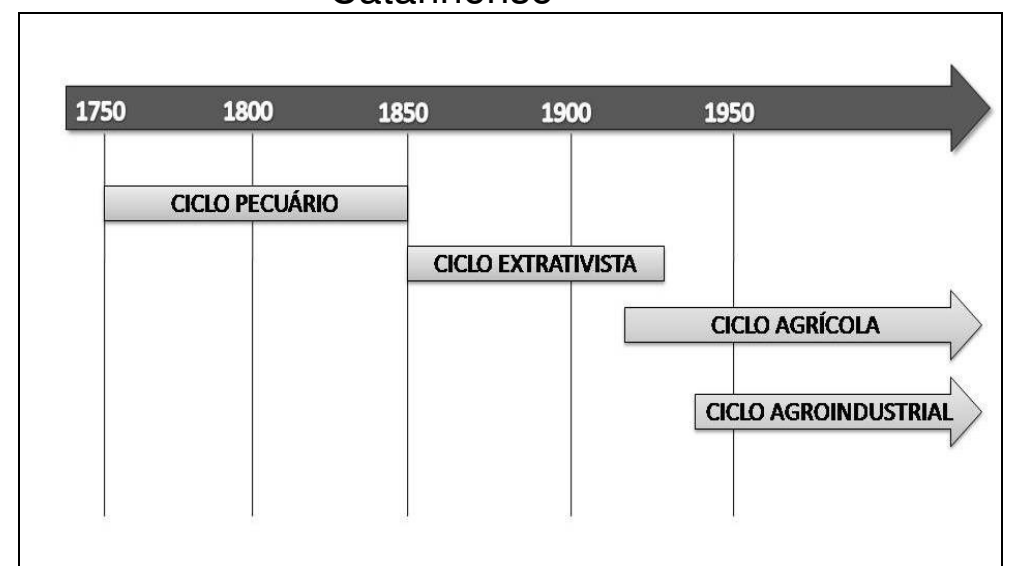

Fonte: Baseado em Bavaresco (2005) e Dmitruk (apud ALBA, 2008).

Os dois primeiros ciclos se desenvolveram na fase da précolonização do Oeste Catarinense, e os dois seguintes na fase da póscolonização. O Ciclo Pecuário teve início por volta de 1750 e se estendeu pelo século seguinte, sendo caracterizado pela criação de gado nos campos de Palmas, com o objetivo de vendê-lo em Sorocaba, São Paulo (DMISTRUK apud ALBA, 2008).

Já o Ciclo Extrativista iniciou-se por volta de 1850 e teve seu fim com o início da colonização italiana e alemã na Região. Esse ciclo foi caracterizado pela extração e venda de bens naturais como a erva-mate e madeiras nobres (DMISTRUK apud ALBA, 2008).

Com o fim da Guerra do Contestado, em 1916, o Oeste Catarinense teve garantida certa estabilidade na definição de seus limites geográficos, pois se definiu então que o estado de Santa 
Catarina seria responsável pela ocupação e administração daquelas terras.

Dessa forma, com o objetivo de consolidar o domínio Catarinense sobre as terras do Oeste, o Estado permitiu que as companhias colonizadoras investissem na ocupação da região, com a venda de terrenos nessa área até então inexplorada (FERRARI, 2003).

No Rio Grande do Sul (RS), a falta de terras para compra, os valores elevados das mesmas e a saturação do solo porque não ocorria rotatividade de cultivo, levaram os produtores rurais a buscarem outras opções de investimentos. Logo, a venda de terras férteis no Oeste Catarinense, por preços reduzidos, despertou 0 interesse dos agricultores gaúchos, descendentes de imigrantes italianos e alemães (WOLOSZYN, 2008).

Esses migrantes traziam consigo a forma de produção mercantil, focada na acumulação de bens, ao contrário dos caboclos habitantes da região, que interpretavam o trabalho como um mero recurso de sobrevivência (WOLOSZYN, 2008).

Com essa nova forma de trabalho dos habitantes da região, o Oeste Catarinense inicia o primeiro ciclo econômico de sua história póscolonização que, segundo Dmitruk (apud ALBA, 2008), pode ser denominado de Ciclo Agrícola.

Paim (2006, p. 126) afirma que "[...] com a vinda dos colonos, estabeleceu-se um sistema produtivo calcado na pequena propriedade, com predomínio da mão-de-obra familiar e de cultivos diversos para comercialização". Os produtos comercializados eram provenientes dos excedentes da produção familiar, ou seja, o que não era consumido na propriedade rural constituía-se em estoque para comercialização, gerando para a família uma nova fonte de renda. Os produtos excedentes também eram utilizados na criação de algumas espécies de animais, como os suínos, que têm como base da sua alimentação o milho, que era um dos principais cultivos agrícolas à época. 
A suinocultura já vinha sendo praticada nas pequenas propriedades do Oeste desde o início da sua colonização, mas em 1950 inicia-se efetivamente um novo ciclo econômico na região, o Ciclo Agroindustrial, quando:

[...] os capitais comerciais se transformam em capitais agroindustriais, caracterizados pelos frigoríficos. Nessa nova realidade, a agricultura familiar passa por um processo de adaptação, onde o "saber" do agricultor é questionado e os novos conhecimentos e técnicas produtivas passam a interferir diretamente na organização do sistema produtivo das propriedades (FERRARI, 2003, p. 32).

Nessa fase, surgem as principais agroindústrias do Oeste Catarinense, dentre elas a Sadia S.A., que absorvia a produção suína da Região, revendendo os produtos para os grandes centros comerciais da época, como São Paulo.

Com sua produção focada no processamento da carne suína para produzir banha, salame, linguiça e presunto, os negócios se expandiam. Contudo, uma crise econômica nos anos de 1960 levou a redução do abate de suínos. Esse fato marca o início do crescimento do mercado avícola no Brasil, porque o preço da carne de frango era mais acessível para a população brasileira, nesse momento em crise (ESPÍNDOLA, 1999).

Ao mesmo tempo, a colonização caracterizada pelas pequenas propriedades rurais, ou pela minifundização, que é o processo de divisão de uma propriedade, transformando-a em propriedades menores, geralmente ocorrendo devido à divisão da propriedade por herdeiros ou devido à venda de partes, gerou o esgotamento dos territórios disponíveis para ocupação, ocasionando, em 1970, o fechamento da fronteira agrícola (FERRARI, 2003; KATO et al., 2008).

Com o objetivo focado na ampliação do mercado consumidor, devido à crise, as agroindústrias reforçam seus investimentos no setor de aves, adaptando seus frigoríficos para o abate e industrialização 
dessa carne e adquirindo matéria-prima dos produtores rurais, que também começavam a investir nesse ramo.

A partir daí aumentou a demanda e, consequentemente, a produção de carne de frango. As vendas se expandiram para os mercados externos, de forma que a exigência por produtos de melhor qualidade impulsionou o processo de modernização da agricultura brasileira. Daí surgiu o Sistema de Produção Integrado, implementado no Oeste Catarinense inicialmente para a produção de suínos e depois para a produção de aves.

O Sistema de Produção Integrado é uma forma de produção organizada, padronizada e de qualidade, de forma a atender as demandas do mercado consumidor (BAVARESCO, 2005).

Segundo Silva (2009, p. 37),

[...] o sistema se desenvolveu aprimorando a industrialização e exigindo patamares crescentes de qualidade no fornecimento de matéria prima pelos agricultores familiares. [...] Os contratos de integração se desenvolveram dando às grandes agroindústrias mecanismos cada vez melhores de controle sobre o processo produtivo.

Resumidamente, o Sistema de Produção Integrado pode ser definido como uma relação contratual entre a agroindústria e o produtor, que estabelece uma parceria na engorda de determinada espécie animal, com o objetivo de aumentar a produtividade.

$\mathrm{Na}$ figura 2 pode ser observado o processo do Sistema de Produção Integrado de aves: 
Figura 2 - Processo do Sistema de Produção Integrado de aves

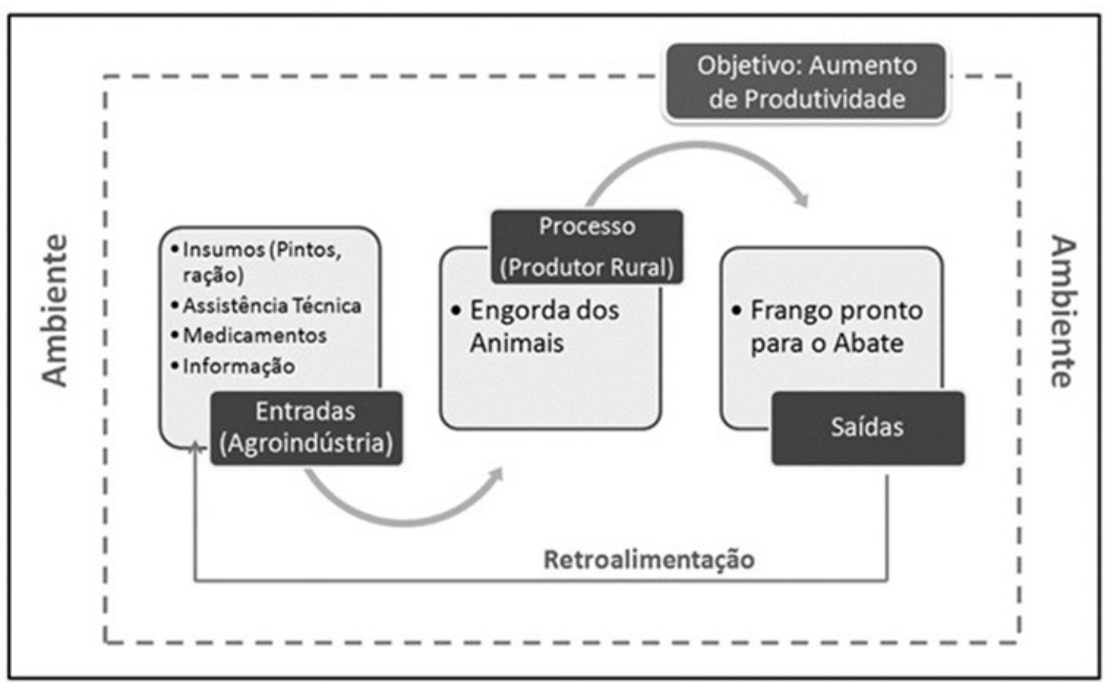

Fonte: Baseado em Bavaresco (2005) e Oliveira (2005).

Nessa parceria, as entradas do processo, retiradas do ambiente externo, são disponibilizadas pela agroindústria aos produtores rurais e consistem em: (i) insumos (filhotes, ração); (ii) assistência técnica; (iii) medicamentos necessários para saúde dos animais; e (iv) informações acerca da forma adequada da criação da espécie. Em contrapartida, o produtor rural é responsável pela disponibilização de instalações adequadas para o desenvolvimento da espécie e pelo monitoramento do processo de engorda dos animais.

O lote de animais com tamanho suficiente para o abate caracteriza a saída do processo produtivo, e nesse momento o mesmo é vendido para a agroindústria fornecedora dos insumos, que fará a industrialização do frango.

Com a venda dos produtos industrializados, a agroindústria obtém recursos que possibilitam a compra de novos insumos, capazes de subsidiar o início de um novo processo de engorda, caracterizada como retroalimentação do sistema produtivo. 


\section{BASE TEÓRICA DA PESQUISA}

Nesta seção são apresentados conceitos e informações que subsidiaram a pesquisa quanto às análises, tendo em vista a problemática e os objetivos estabelecidos. Nessa linha, são abordados conceitos de estudos de usuários da informação e competência em informação, e suas relações com as necessidades de informação.

\subsection{Estudos de Usuários da Informação}

Com o intuito de oferecer serviços que satisfaçam plenamente as necessidades de informação dos usuários das bibliotecas, surgiu, por volta do século XX, a expressão "estudos de usuários" que representa a área da Biblioteconomia responsável por "[...] observar ou questionar os usuários sobre as suas necessidades, preferências, opiniões e avaliações a respeito dos serviços oferecidos ou em atividades de planejamento de produtos/serviços" (DIAS; PIRES, 2004, p. 11).

Como a maioria das áreas de pesquisa, ao longo do tempo, os estudos de usuários da informação também sofreram adaptações, alterações e atualizações em seus objetivos e métodos.

Miranda (2007), a partir da análise das publicações do Annual Review Information Science and Technology (ARIST), identificou uma mudança nas tendências e características dos estudos de usuários a partir de 1986, quando a Abordagem Alternativa dos Estudos de Usuários se sobrepôs a Abordagem Tradicional. Essas abordagens apresentam as seguintes características:

- Abordagem Tradicional: anterior a 1980, e o objeto de estudo eram os sistemas/serviços informacionais, concebendo os usuários apenas como coadjuvantes no processo;

- Abordagem Alternativa: os primeiros estudos a utilizar essa abordagem foram publicados por volta de 1980, quando o usuário é deslocado do papel de coadjuvante para o de objeto do estudo, colocando-o como ponto central de todo o processo informacional. 
Reafirmando a utilização da Abordagem Alternativa, Le Coadic (1998) identifica que até o início da década de 1990 apenas 24\% dos estudos de usuários publicados tratavam realmente das necessidades de informação. A maioria abordava os estudos de usuários como estudo de uso de sistemas de informação. Sendo assim, caracterizavam-se mais como estudos de uso de sistemas e serviços do que de estudos de usuários (apud MIRANDA, 2007).

Após a identificação dessa realidade, Le Coadic (1998 apud MIRANDA, 2007, p. 42) sugere que os estudos "[...] se interessem pela maneira com que um usuário analisa suas necessidades", e também com o processo de saneamento dessas necessidades.

Atualmente, os Estudos de Usuários objetivam

[...] elaborar modelos de comportamento de usuários de informação; estudar os processos de percepções das $\mathrm{NI}$ [necessidades informacionais], de busca e recuperação de informação (em grupos específicos de usuários, em sistemas de informação utilizados por grupos de usuários específicos, etc.); e estudar a satisfação dos usuários com o atendimento às suas NI (MIRANDA, 2007, p. 39).

Calva Gonzáles (2004 apud FLUD, 2006) afirma que as necessidades de informação passam por três fases:

- Surgimento da Necessidade de Informação (NI): ocorre com o reconhecimento de uma anomalia no conhecimento de determinada pessoa. A identificação da necessidade de informação constitui-se como base para a compreensão do restante do processo. As necessidades de informação são originadas a partir do reconhecimento de um problema a ser resolvido, principalmente no desenvolvimento "[...] dos papéis dos indivíduos na vida social, e o mais relevante desses papéis é o papel exercido no trabalho" (MIRANDA, 2007, p. 102).

- Comportamento Informacional: após a identificação da NI, o usuário procura sanar seu problema, recorrendo a diversas fontes de informação, dependendo do tipo de informação de que necessita. 
- Satisfação das Necessidades: é o momento em que o usuário define se as suas necessidades de informação foram atendidas ou não.

O reconhecimento das necessidades de informação é a base para o desenvolvimento de políticas e serviços de informação, por isso identificar as necessidades de informação dos produtores de aves do Oeste Catarinense, integrados às agroindústrias, constituiu-se de uma atividade fundamental que possibilitou a proposição de métodos ideais para a transferência de informações entre a empresa integradora e seus integrados. Porém,

[...] o reconhecimento das NIs não é bastante para satisfazêlas. É necessário proporcionar ao usuário não só a capacidade de entender suas próprias $\mathrm{NI}$, mas também de satisfazê-las e, se possível, com seus próprios meios (MIRANDA, 2006, p. 99).

Portanto, a satisfação das necessidades de informação está diretamente ligada aos meios de saneamento das mesmas. Esses meios devem ser dominados pelos usuários da informação, ou seja, os usuários devem possuir competência em informação, que Ihe possibilita a utilização da informação, caso contrário as necessidades de informação não serão devidamente sanadas.

\subsection{Competência em Informação}

A Ciência da Informação busca delinear o significado de competência em informação estudando o tema desde a década de 1970. No entanto, desde o seu surgimento, essa área de estudos oscila no que tange a sua nomenclatura, "competência em informação" ou "competência informacional". Neste artigo adota-se a expressão "Competência em Informação".

McClelland (1973) diferencia o conceito de competência das conceituações de aptidão, habilidade e conhecimento. Para o autor, aptidão é um talento natural do indivíduo, habilidade é a aplicação prática da aptidão, e conhecimento são os saberes necessários para o 
desenvolvimento de determinada atividade. Já a competência seria o desempenho superior de determinada atividade ou tarefa, ou perante alguma situação.

Fleury e Fleury (2001, p. 188) definem competência como "um saber agir responsável e reconhecido, que implica mobilizar, integrar, transferir conhecimentos, recursos e habilidades, que agreguem valor econômico à organização e valor social ao indivíduo".

Assim, competência pode ser entendida como a utilização prática dos dados analisados, das informações absorvidas e dos conhecimentos adquiridos. Nessa mesma linha, Miranda (2006, p. 108) afirma que competência é "[...] o conjunto de recursos e capacidades colocado em ação nas situações práticas do trabalho: saber (conhecimentos), saber-fazer (habilidades) e saber-ser/agir (atitudes)".

Miranda (2006, p. 110) afirma que o indivíduo, para ser competente em informação, precisa de habilidades para "[...] reconhecer suas necessidades de informação e atendê-las para cumprir objetivos em suas tarefas e resolver seus problemas informacionais". A autora afirma que a competência de um indivíduo provém de seu conhecimento social e de sua inteligência prática. $O$ conhecimento social é adquirido ao longo da história de vida do indivíduo, quando o mesmo questiona a sua trajetória de socialização. Já a inteligência prática, é construída a partir do aprendizado adquirido em situações cotidianas.

Logo, o indivíduo para ser competente em informação necessita de conhecimento social e inteligência prática, pois é a partir do surgimento de problemas, de necessidades e da busca de soluções para os mesmos que a competência em informação é adquirida.

Percebe-se a relação existente entre a competência em informação e as necessidades de informação dos indivíduos. Miranda (2007, p. 91) explica essa relação argumentando que cada necessidade de informação exige o desenvolvimento de competências específicas e, por sua vez, "[...] o desenvolvimento de competências pode levar à formação de novas necessidades". Ou seja, o reconhecimento de uma, 
exige a existência da outra. Sem competência em informação o processo de identificação e solução de uma necessidade de informação torna-se quase impossível.

Ao propor um modelo de avaliação de competência em informação, Belluzzo (2007) define padrões e indicadores de desempenho, baseados em padrões internacionais e ajustados à realidade brasileira, como mostra a Figura 3:

Figura 3 - Padrões e indicadores de desempenho de competência em informação

\begin{tabular}{|c|c|}
\hline $\begin{array}{l}\text { PADRÃO 01: A pessoa competente } \\
\text { em informação determina a } \\
\text { natureza e a extensão da } \\
\text { necessidade de informação. }\end{array}$ & $\begin{array}{l}\text { - Indicador 1.1: Define e reconhece a necessidade de informação. } \\
\text { - Indicador 1.2: Identifica uma variedade de tipos e formatos de fontes de } \\
\text { informaçöes potenciais. } \\
\text { - Indicador 1.3: Considera os custos e benefícios da aquisição da informação } \\
\text { necessária. }\end{array}$ \\
\hline $\begin{array}{l}\text { PADRÃO 02: A pessoa } \\
\text { competente em informação } \\
\text { acessa a informação necessária } \\
\text { com efetividade. }\end{array}$ & $\begin{array}{l}\text { - Indicador 2.1: Seleciona os métodos mais apropriados de busca e/ou } \\
\text { sistemas de recuperação da informação para acessar a informação } \\
\text { necessária. } \\
\text { - Indicador 2.2: Constrói e implementa estratégias de busca delineadas com } \\
\text { efetividade. } \\
\text { - Indicador 2.3: Busca a informação via eletrônica ou com pessoas utilizando } \\
\text { uma variedade de métodos. } \\
\text { - Indicador 2.4: Retrabalha e melhora a estratégia de busca quando } \\
\text { necessário. } \\
\text { - Indicador 2.5: Extrai, registra e gerencia a informação e suas fontes. }\end{array}$ \\
\hline $\begin{array}{l}\text { PADRÃO 03: A pessoa competente } \\
\text { em informação avalia criticamente } \\
\text { a informação e as suas fontes. }\end{array}$ & $\begin{array}{l}\text { - Indicador 3.1: Demonstra conhecimento da maior parte das idéias da } \\
\text { informação obtida. } \\
\text { - Indicador 3.2: Articula e aplica critérios de avaliação para a informação e as } \\
\text { fontes. } \\
\text { - Indicador 3.3: Compara o novo conhecimento com o conhecimento anterior } \\
\text { para determinar o valor agregado, contradições ou outra característica da } \\
\text { informação. }\end{array}$ \\
\hline $\begin{array}{l}\text { PADRÃO 04: A pessoa competente } \\
\text { em informação usa a informação } \\
\text { com efetividade para alcançar um } \\
\text { objetivo ou obter um resultado. }\end{array}$ & $\begin{array}{l}\text { - Indicador 4.1: É capaz de sintetizar a informação para desenvolver ou } \\
\text { completar um projeto. } \\
\text { - Indicador 4.2: Comunica os resultados do projeto com efetividade. }\end{array}$ \\
\hline $\begin{array}{l}\text { PADRÃO 05: A pessoa competente } \\
\text { em informação compreende as } \\
\text { questões econômicas, legais e } \\
\text { sociais da ambiência do uso da } \\
\text { informação e acessa e usa a } \\
\text { informação ética e legalmente. }\end{array}$ & $\begin{array}{l}\text { - Indicador 5.1: Demonstra compreensão sobre as questões legais, éticas e } \\
\text { sócio-econômicas que envolvem a informação, a comunicação e a } \\
\text { tecnologia. } \\
\text { - Indicador 5.2: Cumpre as leis, regulamentos, políticas institucionais e } \\
\text { normas relacionadas ao acesso e uso das fontes de informação. } \\
\text { - Indicador 5.3: Indica as fontes de informação nas comunicações do produto } \\
\text { ou resultados. }\end{array}$ \\
\hline
\end{tabular}

Fonte: Belluzzo (2007, p. 95). 
Esses padrões e indicadores se apresentam como uma base para identificar a competência em informação de populações específicas, desde que adaptadas à realidade dessas populações.

\section{METODOLOGIA DA PESQUISA}

Trata-se de um estudo exploratório qualitativo. Conforme Gil (1989, p. 44), a pesquisa exploratória visa "[...] proporcionar uma visão geral, de tipo aproximativo, acerca de determinado fato", problema ou situação. No caso da pesquisa que deu origem a este artigo, o problema refere-se às necessidades de informação e à competência em informação dos produtores de aves do Sistema Integrado de Produção da agroindústria Sadia S.A. do Oeste de Santa Catarina.

A pesquisa foi delimitada ao universo de produtores de aves integrados da agroindústria Sadia S.A., empresa pioneira do setor, residentes nos municípios de Ipumirim e Lindóia do Sul, que totaliza cinquenta produtores. Desse universo, sete produtores concordaram participar da pesquisa.

Para o levantamento de dados primários optou-se por utilizar a técnica da observação direta intensiva e extensiva. Na observação direta intensiva, utilizou-se como instrumento de coleta de dados a entrevista estruturada. A padronização da entrevista possibilitou a comparação das respostas e a análise dos discursos, com o objetivo de identificar as necessidades de informação dos sujeitos, bem como o reconhecimento das competências em informação deles. Para a observação direta extensiva foram aplicados formulários, constituídos por um número ordenado de perguntas, com o objetivo de caracterizar os sujeitos. Esse instrumento foi preenchido pelo pesquisador no momento da entrevista.

Como exposto, foram entrevistados sete avicultores, dentre os quais, dois residentes no município de Ipumirim e cinco de Lindóia do Sul, com média de idade de 46 anos. Participaram da pesquisa tanto 
integrados recentes do Sistema de Produção Integrado, quanto avicultores com maior experiência nesse método produtivo. Consta que um dos entrevistados tem apenas dois anos de integração e outro é integrado há 31 anos, sendo que o tempo médio de integração dos avicultores pesquisados é de 22 anos.

Quanto ao nível de escolaridade, identificou-se que todos os entrevistados cursaram apenas as primeiras séries do Ensino Fundamental e entre os meios de comunicação disponíveis na propriedade pode-se observar a predominância da televisão (100\%), do rádio (100\%) e do telefone (100\%). Quanto à Internet, apenas $28 \%$ dos sujeitos da pesquisa têm acesso e a utilizam principalmente para pesquisar sobre equipamentos agrícolas, doenças, novidades na área de produção de aves, bem como acessar a redes sociais. Observou-se também que, devido a dificuldades na entrega de correspondências nas propriedades rurais, há uma baixa adesão dos avicultores à assinatura de jornais e de revistas.

As propriedades rurais do Oeste Catarinense são, na sua maioria minifúndios, ou seja, pequenas propriedades rurais que, no Senso Agropecuário de 1996, segundo o IBGE (2011), apresentavam uma média de extensão de 32 hectares.

Para a análise dos depoimentos coletados, utilizou-se a técnica do Discurso do Sujeito Coletivo (DSC), que é um procedimento metodológico criado e definido pelos professores Fernando Lefevre e Ana Maria Lefevre. Para os autores, o DSC é

\footnotetext{
O resgate do sentido das opiniões coletivas, que desemboca num ou num conjunto de discursos, é um processo complexo, subdividido em vários momentos, efetuado por meio de uma série de operações realizadas sobre 0 material verbal coletado nas pesquisas (apud MENDONÇA, 2007, p. 156).
}

Dessa forma, a partir de uma série de discursos, obtidos por meio de entrevistas, a técnica do DSC reúne "[...] sob a forma de discursos únicos redigidos na primeira pessoa do singular, conteúdos de 
depoimentos com sentidos semelhantes", onde a opinião, crenças e valores de uma coletividade são representados de forma única (LEFEVRE; LEFEVRE; MARQUES, 2009, p. 1194).

Para a análise dos discursos individuais, e posterior montagem do DSC, as entrevistas foram transcritas e, sobre os respectivos conteúdos, foram aplicadas as seguintes figuras metodológicas, propostas por Lefevre e Lefevre (2003):

- Expressões chaves (ECH): são trechos literais retirados dos depoimentos e que representam a essência de cada discurso;

- Ideia central (IC): representação sintética do sentido do tema tratado em cada discurso;

- Ancoragem (AC): da mesma forma que a IC, a AC representa sinteticamente as crenças, valores e ideologias presentes em cada discurso individual;

- Discurso do Sujeito Coletivo (DSC): é a integração, em um único discurso apresentado na primeira pessoa do singular, das $\mathrm{ECH}$ que possuem a mesma IC e AC, caracterizando-se como uma fala social da coletividade estudada.

\section{COMPETÊNCIA EM INFORMAÇÃO E NECESSIDADES DE INFORMAÇÃO DOS AVICULTORES A PARTIR DO DSC}

A competência em informação de um indivíduo está relacionada ao domínio que ele tem sobre a informação. Em outras palavras, ser competente em informação é ter capacidade de acessar, armazenar, recuperar e compreender a informação de forma eficaz e eficiente. Belluzzo (2007) desenvolveu um conjunto de padrões e indicadores para a avaliação de competência em informação, conforme Figura 3. Com base nesses padrões e indicadores, definiu-se um conjunto básico de três padrões e seis indicadores para a identificação da competência em informação dos avicultores para o desenvolvimento de suas atividades cotidianas (QUADRO 1). Para tal, foram consideradas as peculiaridades 
da área, o contexto e, em especial, o perfil dos produtores levantado a partir dos dados coletados por meio do Formulário de Caracterização.

Quadro 1 - Padrões e indicadores para avaliação da competência em informação dos avicultores

PADRÃO $\mathbf{1}-\begin{gathered}\text { O avicultor competente em informação determina a } \\ \text { natureza e a extensão da necessidade de informação }\end{gathered}$
INDICADOR DE DESEMPENHO 1.1
Define e reconhece a necessidade de informação
INDICADOR DE DESEMPENHO 1.2
Identifica uma variedade de tipos e formatos de fontes de informação
potenciais
INDICADOR DE DESEMPENHO 1.3
Considera os custos e benefícios da aquisição da informação necessária
PADRÃO 2 - O avicultor competente em informação acessa a
informação necessária com efetividade
BNDICADOR DE DESEMPENHO 2.1
métodos informação eletrônica ou com pessoas utilizando uma variedade de
INDICADOR DE DESEMPENHO 2.2
Refaz a estratégia de busca de informações quando necessário
PADRÃO 3 - O avicultor competente em informação, usa a informação
para alcançar um resultado
INDICADOR DE DESEMPENHO 3.1
Utiliza a informação para melhoria do processo produtivo e aumento da
produtividade.

Fonte: Baseado em Belluzzo (2007, p. 95).

\subsection{Competência em Informação dos Produtores de Aves}

Com base no DSC, a análise da competência em informação dos avicultores parte do pressuposto expresso nos padrões apresentados no Quadro 1: o avicultor competente em informação determina a natureza e a extensão da sua necessidade de informação, acessa a informação necessária com efetividade e usa a informação para alcançar um resultado. 


\section{PADRÃO 1 - 0 avicultor competente em informação determina a natureza e a extensão da necessidade de informação}

Miranda (2006, p. 110) afirma que a competência de um indivíduo provém de duas fontes: do conhecimento social e da inteligência prática. Conforme pode ser observado no trecho a seguir, extraído do DSC, a inteligência prática, que é construída a partir do aprendizado adquirido em situações cotidianas, reduziu a necessidade de o indivíduo buscar informações para o desenvolvimento das suas atividades cotidianas.

Não posso dizer que conheço tudo e é fato que quanto mais informação melhor, porém, devido aos anos de prática no desenvolvimento da atividade de criação de frangos de corte, não existe mais tanta necessidade de buscar informações.

Porém, como expresso no Indicador de Desempenho 1.1, e observando a fala transcrita abaixo, percebe-se que 0 avicultor consegue reconhecer suas necessidades de informação:

[...] busco informações quando percebo a necessidade. Por exemplo, quando identifico a existência de algum problema no aviário, como doenças ou pouco desenvolvimento dos frangos.

Tendo em vista o Indicador de Desempenho 1.2, de que o avicultor competente identifica uma variedade de tipos e formatos de fontes de informação potenciais, constatou-se que os sujeitos da pesquisa identificam uma variedade de fontes de informação, de acordo com o que é disponibilizado pela empresa integradora, como consta no trecho a seguir:

Além do técnico agrícola, a empresa integradora repassa as informações necessárias através de reuniões, pelo rádio, por jornais e também por folders.

Com base nas transcrições do DSC abaixo destacadas, observado o Indicador de Desempenho 1.3, pode-se afirmar que os 
participantes da pesquisa, avicultores dos municípios do Oeste Catarinense, Ipumirim e Lindóia do Sul, consideram os benefícios da aquisição da informação necessária, todavia, não se referem aos custos da informação.

[...] A empresa integradora [...] promove cursos sobre a criação de frangos de corte, onde normalmente participo para buscar mais informações e orientações, para aprender coisas novas e a realizar as atividades cotidianas da maneira correta.

[...] é fato que quanto mais informação melhor.

[...] essas informações repassadas pelos técnicos agrícolas são úteis na maioria das vezes, pois conseguem resolver problemas encontrados no aviário e sempre trazem alguma novidade sobre a atividade.

O DSC apenas não identificou parte de um dos indicadores do padrão 1 - o que tange ao custo da informação. Esse fato influencia na solução de determinadas necessidades de informação, pois é essa avaliação de custo/benefício que "[...] levará a pessoa a decidir-se por se engajar ou não na busca efetiva pela informação" de modo racional (MIRANDA, 2007, p. 47).

\section{PADRÃO 2 - 0 avicultor competente em informação acessa a informação necessária com efetividade}

Quanto ao Indicador de Desempenho 2.1, o avicultor competente em informação busca informações utilizando uma variedade de métodos. Constatou-se que os sujeitos da pesquisa buscam somente uma fonte de informação para o atendimento das suas necessidades de informação, conforme pode ser visto no trecho a seguir:

[...] Quando identifico a existência de algum problema no aviário [...] costumo recorrer ao técnico agrícola. 
Ao mesmo tempo, não foi constatada nenhuma evidência no DSC de que o avicultor refaz a estratégia de busca de informações quando necessário, conforme Indicador de Desempenho 2.2.

\section{PADRÃo 3 - 0 avicultor competente em informação, usa a informação para alcançar um resultado}

O Padrão 3 diz respeito à utilização da informação para o alcance de determinado resultado, no caso dos avicultores, para a melhoria do processo produtivo e o aumento da produtividade. A utilização da informação para esse fim pode ser observada nas falas do DSC citadas a seguir:

[...] A empresa integradora [...] promove cursos sobre a criação de frangos de corte, onde normalmente participo para buscar mais informações e orientações, para aprender coisas novas e a realizar as atividades cotidianas da maneira correta.

[...] essas informações repassadas pelos técnicos agrícolas são úteis na maioria das vezes, pois conseguem resolver problemas encontrados no aviário e sempre trazem alguma novidade sobre a atividade.

A análise permite concluir que os avicultores sujeitos da pesquisa têm determinado nível de competência em informação, tendo em vista a presença de $50 \%$ dos indicadores de competência em informação no DSC. Porém, percebe-se principalmente a necessidade de eles desenvolverem a capacidade de: (i) identificar uma variedade de tipos e formatos de fontes de informação potenciais (Indicador de desempenho 1.2); (ii) buscar informação eletrônica ou com pessoas utilizando uma variedade de métodos (Indicador de desempenho 2.1); (iii) refazer a estratégia de busca de informações quando necessário (Indicador de desempenho 2.2). 


\subsection{Necessidades de Informação dos Produtores de Aves}

O profissional da informação não está acostumado a lidar com todos os tipos de públicos, sendo que alguns grupos de usuários podem ser considerados como emergentes e não-convencionais, dentre eles os produtores rurais (CAVALCANTE; DIAS, 2001). Em consequência, os bibliotecários e demais profissionais da informação demandam pouca atenção às necessidades desse público.

Atualmente, quando "[...] os estudos de necessidade de informação de determinados grupos de indivíduos ou empresas não precisam, obrigatoriamente, estar atrelados a uma biblioteca ou sistema de informação", o mercado de atuação de bibliotecários expande-se e a sociedade é beneficiada, em especial, os públicos emergentes que se tornam o foco, muitas vezes, de estudos sobre informação, da sua forma mais ampla (NASCIMENTO, 2004, p. 50).

Tendo em vista esse cenário e o DSC, foram identificadas as seguintes necessidades de informação dos produtores de aves, integrados da empresa Sadia S.A., sujeitos da pesquisa:

- Informação para solução de problemas: as necessidades de informação normalmente surgem quando ocorre a identificação de um problema ou uma anomalia, independentemente da origem do problema. Isso pode ser percebido quando os avicultores afirmam que procuram o técnico agrícola quando têm um problema no aviário e, principalmente, quando encontram dificuldades para resolvê-lo.

Percebe-se assim a expectativa dispensada ao especialista na atividade de produção de aves pelos produtores integrados, caracterizado como a principal fonte de informação utilizada para a solução dos problemas encontrados no desenvolvimento das atividades cotidianas. Logo, parece ser imprescindível a capacitação dos técnicos agrícolas da empresa integradora para atender essa demanda, bem como para interagir e compreender as necessidades de informação dos produtores. 
- Informação para atualização: a pesquisa revelou a necessidade dos avicultores quanto à busca por novos conhecimentos $e$ novidades técnicas. Segundo Le Coadic (2004, p. 5), essa necessidade é básica de todos os indivíduos, "[...] seja pelo simples prazer de conhecer (Freud), de estar informado sobre os acontecimentos políticos, os progressos da ciência e da tecnologia, ou pelo prazer menos simples de estar a par dos últimos temas".

Essa necessidade é identificada quando os avicultores afirmam que participam das reuniões organizadas pela empresa integradora, bem como quando solicitam que a mesma disponibilize o acesso a mais informações sobre novidades da área.

O saneamento dessa demanda, além de possibilitar o aprendizado contínuo, fará com que os avicultores estejam mais atualizados sobre a atividade de produção de frangos de corte, o que poderá proporcionar à empresa integradora o alcance de melhores resultados.

- Informação para o aperfeiçoamento do processo produtivo: com o objetivo de se destacarem frente ao mercado consumidor, cada vez mais, as organizações buscam desenvolver produtos e serviços de qualidade para o cliente. Para tanto, investem quantias representativas de recursos na melhoria dos seus processos produtivos, seja na busca pelo desenvolvimento de produtos com alto nível de qualidade, seja na rapidez dos processos. Porém, apenas investimentos financeiros não são suficientes para as empresas alcançarem esses objetivos, é necessário também o engajamento de todos os stakeholders nessa caminhada.

Pode-se perceber o interesse dos avicultores em participar da busca por essa qualidade, pois quando questionados se participavam dos cursos oferecidos pela empresa integradora e o que buscavam com isso, revelaram o interesse de aperfeiçoar a parte do processo produtivo que Ihes diz respeito, ou seja, a produção da matéria prima, afirmando 
que participam dos cursos para conhecer as melhores formas de desenvolvimento das atividades cotidianas.

Tendo em vista essa motivação dos produtores integrados da Sadia S.A., as empresas integradoras poderia desenvolver e implementar estratégias para a capacitação dos avicultores, o que contribuiria para melhorar os processos e atingir melhores resultados na produção, resultando em benefícios para ambas as partes.

- Informação sobre objetivos futuros: identificou-se a partir do DSC a necessidade de os avicultores conhecerem a missão da empresa integradora, bem com sua visão e projetos para o futuro.

Oliveira (2009), afirma que a missão deve deixar explícito aonde a empresa quer chegar, e a visão representa os objetivos a longo prazo da empresa, ou seja, é a posição em que deseja estar num determinado período de tempo e as competências necessárias para tal.

Ter claros esses elementos facilita o alcance dos propósitos e objetivos da empresa, bem como a implantação dos planos e estratégias da mesma. Portanto, a divulgação desses ideais torna o produtor integrado participante dos propósitos organizacionais.

\section{CONSIDERAÇÕES FINAIS}

As necessidades de informação dos produtores de aves integrados da agroindústria Sadia S.A., sujeitos da pesquisa, para o desenvolvimento de suas atividades cotidianas foram identificadas por meio da Análise do Discurso Coletivo (DSC). Percebeu-se que, devido à experiência na atividade, alguns problemas rotineiros dos avicultores já podem ser resolvidos por eles sem necessitar de novas informações. Porém, os avicultores ainda carecem de algumas informações importantes para a melhoria dos processos de criação de frangos, bem como necessitam acesso à informação atualizada para a melhoria da qualidade de vida. Quanto aos tipos de informação necessária, destacase: informação para a solução de problemas, para a atualização e o 
aperfeiçoamento do processo produtivo, e sobre objetivos futuros da Empresa.

As informações do DSC relacionadas aos padrões e indicadores de competência em informação definidos possibilitaram verificar a competência em informação, bem como as lacunas que se apresentam no domínio da informação pelos avicultores pesquisados. Constatou-se, sobretudo, que esses avicultores, para serem competentes em informação, precisam saber:

\section{Identificar uma variedade de tipos e formatos de fontes de} informação potenciais: para os avicultores desenvolverem essa capacidade a empresa integradora pode criar mecanismos diversos de transmissão de informação, de modo que, ao identificar um problema, o avicultor possa recorrer a diferentes fontes de informação, além do técnico agrícola. Uma sugestão é a criação de um banco de dados onde estariam armazenadas informações sobre problemas que podem ocorrer em aviários, juntamente com explicações necessárias para a resolução dos mesmos. Observa-se, porém, a necessidade de capacitação dos avicultores para a adequada utilização do serviço, considerando-se, sobretudo, o distanciamento dos produtores com as informações e os produtos tecnológicos.

\section{Buscar informação eletrônica ou com pessoas utilizando} uma variedade de métodos: para a melhoria dessa capacidade podese levar em consideração a necessidade de treinamento dos avicultores para o uso das tecnologias de informação e comunicação (TICs), a fim de facilitar o acessar à informação eletrônica, bem como, a disponibilização de meios diversos de transmissão de informações da empresa integradora para os produtores, além dos já disponíveis.

\section{Refazer a estratégia de busca de informações quando} necessário: alinhando-se aos itens anteriores, essa capacidade pode ser desenvolvida por meio da disponibilização de mais canais de comunicação entre empresa e produtor, como o atendimento telefônico e on-line para solução de dúvidas e a disponibilização de um centro de 
atendimento presencial na empresa, aberto para visitas dos avicultores, o que também poderia contribuir para o estreitamento da relação entre integrado e integrador.

Essas são apenas sugestões que não foram submetidas à análise de viabilidade. Sugere-se, portanto, que estudos futuros identifiquem e analisem métodos adequados para a transferência de informações oportunas aos produtores de aves, tendo em vista a competência em informação e as necessidades de informação deles.

Por fim, o conjunto de padrões e indicadores definidos para avaliar a competência em informação dos avicultores pode servir como base para estudos da competência em informação de avicultores de outras agroindústrias e regiões, desde que respeitadas as particularidades.

\section{REFERÊNCIAS}

ALBA, Rosa Salete (Org.). Estudos de geografia agrária do oeste catarinense. Chapecó: Argos, 2008.

BAVARESCO, Paulo Ricardo. Ciclos econômicos regionais: modernização e empobrecimento no extremo oeste catarinense. Chapecó: Argos, 2005.

BELLUZZO, Regina Celia Baptista. Construção de mapas:

desenvolvendo competências em informação e comunicação. 2. ed. Bauru: Cá entre Nós, 2007.

CAVALCANTE, Lídia Eugenia; DIAS, Edna Leite. O mercado de informação no setor turístico brasileiro. Informação e Informação, Londrina, v. 6, n. 2, p. 121-129, jul./dez. 2001.

DIAS, Maria Matilde Kronka; PIRES, Daniela. Usos e usuários da informação. São Carlos: EDUFSCar, 2004.

ESPÍNDOLA, Carlos Jose. As agroindústrias no Brasil: "o caso Sadia". Chapecó: Grifos, 1999. 
FERRARI, Dilvan Luiz. Agricultura familiar, trabalho e desenvolvimento no oeste de Santa Catarina. 2003. Dissertação (Mestrado em Desenvolvimento Econômico, Espaço e Meio Ambiente) Instituto de Economia, UNICAMP, 2003. Disponível em: $<$ http://www.bibliotecadigital.unicamp.br/document/?code=vtls000308780 \&opt=1>. Acesso em: 10 jun. 2014.

FLEURY, Maria Tereza Leme; FLEURY, Afonso. Construindo o conceito de competência. Revista Administração Contemporânea, Curitiba, v. 5, n. especial, 2001. Disponível em: $<$ http://www.scielo.br/scielo.php?script=sci_arttext\&pid=S141565552001000500010\&lng=en\&nrm=iso >. Acesso em: 10 jun. 2014.

FLUD, Paula Barreto. Necessidade e uso de informação para negócios pelos gestores do setor supermercadista de Campo Grande/MS. 2006. Dissertação (Mestrado em Ciência da Informação) Programa de Pós-Graduação em Ciência da Informação da UNB, Brasília, 2006. Disponível em: <http://repositorio.bce.unb.br/bitstream/10482/5532/1/2006_Paula\%20B arreto\%20Flud.pdf>. Acesso em: 10 jun. 2014.

GIL, Antonio Carlos. Métodos e técnicas de pesquisa social. 2. ed. São Paulo: Atlas, 1989.

IBGE. Sinopse do censo demográfico 2010. 2011. Disponível em: <http://www.ibge.gov.br/home/estatistica/populacao/censo2010/calendar io.shtm>. Acesso em: 10 jun. 2014.

KATO, Maria do Socorro de A. et al. Alternativas para recuperação de áreas degradadas, desenvolvimento sustentável e fortalecimento da agricultura familiar na Amazônia. Brasília: IBICT, 2008. Disponível em: <http://www.canalciencia.ibict.br/pesquisa/0228-Recuperacaoareas-degradadas-amazonia.html>. Acesso em: 10 jun. 2014.

LE COADIC, Y. Francois. A ciência da informação. 2. ed. Brasília: Briquet de Lemos, 2004.

LEFEVRE, Fernando; LEFEVRE, Ana Maria Cavalcanti. O discurso do sujeito coletivo: um novo enfoque em pesquisa qualitativa. Caxias do Sul: Educs, 2003.

LEFEVRE, Fernando; LEFEVRE, Ana Maria Cavalcanti; MARQUES, Maria Cristina da Costa Marques. Discurso do sujeito coletivo, complexidade e auto-organização. Ciência e Saúde Coletiva, Rio de Janeiro, v. 14, n. 4, ago. 2009. Disponível em: $<$ http://www.scielo.br/scielo.php?script=sci_arttext\&pid=S1413$81232009000400025 \&$ Ing=en\&nrm=iso >. Acesso em: 10 jun. 2014. 
MCCLELLAND, David C. Testing for competence rather than for intelligence. American Psychologist, Washington, n. 28, p. 1-14, 1973.

MENDONÇA, A. V. M. O uso da análise do discurso do sujeito coletivo em ciência da informação. In: MULLER, Suzana Pinheiro Machado.

(Org.). Métodos para a pesquisa em ciência da informação. Brasília: Thesaurus, 2007. p. 149-170.

MIRANDA, Silvania V. Como as necessidades de informação podem se relacionar com as competências informacionais. Ciência da Informação, Brasília, v. 35, n. 3, dez. 2006. Disponível em:<http://www.scielo.br/scielo.php?script=sci_arttext\&pid =S0100$19652006000300010 \&$ Ing=pt\&nrm=iso >. Acesso em: 10 jun. 2014.

MIRANDA, Silvania V. Identificação de necessidades de informação e sua relação com competências informacionais: o caso da supervisão indireta de instituições financeiras no Brasil. 2007. Tese (Doutorado em Ciência da Informação) - Programa de Pós-Graduação em Ciência da Informação da UNB, Brasília, 2007. Disponível em: $<$ http://bdtd.bce.unb.br/tedesimplificado/tde_busca/arquivo.php? codArquivo=1195>. Acesso em: 10 jun. 2014.

NASCIMENTO, Maria de Jesus. Informação: insumo básico para o desenvolvimento do setor de turismo em Santa Catarina. Perspectivas em Ciência da Informação, Belo Horizonte, v. 9, n. 1, p. 48-69, jan./jun. 2004.

OLIVEIRA, Djalma de Pinho Rebouças. Planejamento estratégico: conceitos, metodologia, práticas. 26. ed. São Paulo: Atlas, 2009.

OLIVEIRA, Djalma de Pinho Rebouças. Sistemas, organização e métodos: uma abordagem gerencial. 15. ed. São Paulo: Atlas, 2005.

PAIM, Elison Antonio. Aspectos da constituição histórica da região oeste de Santa Catarina. Saeculum, João Pessoa, v. 14, p. 121-138, jan.jun. 2006. Disponível em:

<http://www.biblionline.ufpb.br/ojs/index.php/srh/article/viewFile/11346/6 460>. Acesso em: 10 jun. 2014.

SILVA, Elvio Izaias. O papel da avicultura na construção do território e na reprodução social da agricultura familiar: o caso de Chapecó e Quilombo no oeste catarinense. 2009. Dissertação (Mestrado em Agroecossistemas) - Universidade Federal de Santa Catarina, Florianópolis, 2009. 
WOLOSZYN, Noeli. Em busca da terra: colonização e exploração de madeiras no oeste catarinense. Concórdia: Universidade do Contestado, 2008. Disponível em:

<http://www.uncnet.br/apps/pesquisa/pdf/historia/BUSCA_TERRA_COL ONIZACAO_EXPLORACAO_MADEIRAS_OESTE_CATARINENSE.pdf> . Acesso em: 10 jun. 2014.

Title:

Information needs and information literacy of the poultry farmers embedded in the agribusiness society Sadia S.A. of the west of Santa Catarina, Brazil

\section{Abstract}

Introduction: This study evaluates information needs and information literacy of poultry farmers of the integrated system of the agribusiness society Sadia S.A. in the west of Santa Catarina, Brazil.

Objective: Analyze information needs and information literacy of poultry farmers of the integrated system of the agribusiness society Sadia S.A. in the west of Santa Catarina, Brazil.

Methodology: This is an exploratory qualitative study, where a structured interview and a form for the sample identification were instruments used for collecting the data. The technique of the Collective Discourse Subject and a set of indicators for information competence evaluation were used for the data analysis.

Results: The results show that the poultry farmers need information for problem solution, updating and improvement of the production process, and also for the future aims of the integrator company. As regards information competence, it was found that the poultry farmers acknowledge part of information they need, however, it is not enough to satisfy their needs.

Conclusion: In order to become information literacy the poultry farmers need to develop the following aspects: identify a range of types and formats of the potential source of information; search for information using a variety of methods; redo the information searching strategy when necessary.

Keywords: Agribusiness - the west of Santa Catarina, Brazil. Sadia S. A. Aviculture. Information literacy - poultry farmers. Information needs - poultry farmers.

\section{Titulo}

Necesidades de información y alfabetización en información del productores de aves integrados de la agroindustria Sadia S.A. del oeste de Santa Catarina, Brasil 


\section{Resumen}

Introducción: Se trata de un estudio de evaluación de las necesidades de información y la alfabetización en información del productores de aves del sistema de integración de la agroindustria Sadia S.A. del Oeste Catarinense.

Objetivo: Analizar las necesidades de información y la alfabetización en información del productores de aves del sistema de integración de la agroindustria Sadia S.A. del Oeste Catarinense.

Metodología: Estudio exploratorio cualitativo, donde los instrumentos de colecta de datos utilizados fueron entrevista estructurada y formulario para la caracterización de los sujetos de la muestra. Para el análisis de los datos ha sido utilizada la técnica del Discurso del Sujeto Colectivo y un conjunto de indicadores para evaluación de la alfabetización en información.

Resultados: Se ha identificado que los avicultores tienen necesidades de información para la solución de problemas, para actualización y perfeccionamiento del proceso productivo, y acerca de los objetivos futuros de la empresa integradora. En cuanto a la alfabetización en información, se ha constatado que los avicultores reconocen parte de las informaciones de que necesitan, sin embargo, no lo suficiente para atender sus necesidades.

Conclusiones: Los avicultores, para ser competentes en información, necesitan desarrollar los siguientes aspectos: identificar una variedad de tipos y formatos de fuentes de información potenciales, buscar información utilizando una variedad de métodos, rehacer la estrategia de búsqueda de informaciones cuando necesario.

Palabras- clave: Agroindustrias - oeste catarinense. Sadia S.A. Avicultura. Alfabetización en información - avicultores. Necesidades de información avicultores.

Recebido em: 27/06/2014

Aceito em: 28/03/2015 